\title{
Characterisation of the Lateral Resistance of Stapled Shear Walls
}

\author{
Roberto Aranda $^{1 *}$, Alexander Salenikovich ${ }^{2}$, J. Daniel Dolan ${ }^{3}$, and Peter Dechent ${ }^{4}$ \\ ${ }^{1}$ MSc candidate, Department of Civil Engineering, Universidad de Concepción, Chile \\ ${ }^{2}$ Professor, Department of Wood and Forest Sciences, Université Laval, Canada \\ ${ }^{3}$ Professor, Composite Materials and Engineering Center, Washington State University, USA \\ ${ }^{4}$ Professor, Department of Civil Engineering, Universidad de Concepción, Chile \\ *Corresponding author's e-mail: roarandam@gmail.com
}

\begin{abstract}
Shear walls are the major components of the lateral-force-resisting system (LFRS) in light-frame wood buildings. With the growing popularity of mid-rise prefabricated light-frame wood construction, engineers need basic design information on the shear walls to design and produce safe structures in case of high winds and earthquakes. The racking resistance of light-frame shear walls depends on many factors, including sheathing and hold-down devices and, most importantly, sheathing-to-framing fastenings. While the performance of nailed shear walls has been studied extensively, and design information is included in the design codes, there is little information on stapled shear walls, specifically in the US and Canada. The cost of staples is significantly less than that of equivalent nails; hence, the use of staples instead of nails would allow cost savings in mass production if they provide sufficient resistance and displacement capacity in the engineered shear walls. This paper presents the results of a pilot study which was focused on the comparison of the performance of nailed and stapled shear walls in laboratory tests under monotonic and cyclic loading in accordance with ASTM E564 and E2126, respectively. Several series of tests were performed on 2.4-m (8-ft) square shear walls with 11-mm (7/16-in) OSB sheathing with various hold-downs and various spacing of sheathing staples and nails on the perimeter of the sheathing panels (5-cm (2-in), 10-cm (4-in) and 15-cm (6-in)) and 19-mm and 10-mm edge distances. The staples were 16-gauge (50-mm (2-in) long with 11-mm (7/16-in) crown). The nails were $8 \mathrm{~d}$ box steel wire nails (63-mm (21/2-in) long with 2.87-mm (0.113-in) diameter). The test results revealed a similar performance of the nailed and stapled shear walls, and the need for careful detailing. Therefore, prefabrication of walls in the factory settings is preferable to the on-site construction to allow the production quality control.
\end{abstract}

\section{KEYWORDS}

Wood light-frame construction; Monotonic and cyclic tests; Edge distance; Sheathing-to-framing staple and nail fastenings. 


\section{INTRODUCTION}

Wood light-frame shear wall structures are commonly used for residential and non-residential buildings, the reasons behind the popularity and widespread application of wood framing and sheathing is the availability of wood structural components and the system's good seismic and wind performance. Extensive research has been conducted to evaluate the seismic behavior of wood light-frame shear walls to improve the state of the art knowledge. The racking resistance of light-frame shear walls depends on many factors, including sheathing type and thickness, holddown devices, and most importantly, sheathing-to-framing fastenings. While the performance of nailed shear walls has been studied extensively by Dolan (1989), Kassal and Leichti (1992), Salenikovich (2000), Gatto and Uang (2002), Toothman (2003), Leichti et al. (2006), and others for monotonic and cyclic behaviour with different nails, and design information is included in the design codes, there is little information on the response of stapled shear walls.

Over the years, the theoretical deflection of shear walls has been estimated using one of two equations presented in the SDPWS (AWC 2008). These equations add the different sources of deflection to estimate total shear wall deflection. The linear 3-term equation has been developed to simplify the calculations using a $\mathrm{G}_{\mathrm{a}}$ value that combines the $\mathrm{G}_{\mathrm{v}} \mathrm{t}_{\mathrm{v}}$ and $\mathrm{e}_{\mathrm{n}}$ terms in the non-linear 4term equation. The $\mathrm{G}_{\mathrm{a}}$ value is prescribed so that the two equations provide the same deflection estimate at the point of LRFD design, or 1.4 times the ASD design value.

This paper is focused on the comparison of performance parameters of stapled and nailed walls through static and cyclic tests conducted according to ASTM Standards, and highlights the potential improved performance when staples are used as well as an issue of the accuracy of the deflection estimation provided by the two equations included in the SDPWS (AWC 2008) document. Subsequent publications will investigate the deflection equations' performance in detail.

\section{METHODS}

\section{Specimens}

Shear wall specimens were constructed with sheathing, framing, fastening, anchorage and connections as shown in Table 1. The shear walls were constructed according to the ASTM E564 and ASTM E2126 (ASTM 2011) requirements, with Spruce-Pine-Fir (SPF) 38-mm by 139-mm (2-in by 6-in) framing and studs spaced at 406-mm (16-in) o.c. The wall consisted of a single bottom plate, a double top plate, double end studs, and double middle studs (where an increased framing thickness was required for closer sheathing nail spacing.) All sheathing was 11-mm (7/16 in) thick Oriented Strand Board (OSB) rated sheathing. The walls were 2.44-m (8-ft) long and tall (aspect ratio $=1.0$.) The staples used to attach the sheathing to the studs were 16-gauge 50- mm (2-in) long with a 11-mm (7/16-in) crown. The nails were $8 \mathrm{~d}$ steel wire box nails (63-mm (21/2- in) long with $2.87-\mathrm{mm}(0.113$-in) diameter.) Various sheathing staple and nail spacings were used for the tests. Edge fastener spacings of $5 \mathrm{~cm}(2 \mathrm{in}), 10 \mathrm{~cm}$ (4 in) and $15 \mathrm{~cm}(6 \mathrm{in})$ were used and the edge distances were $19 \mathrm{~mm}$ and $10 \mathrm{~mm}$, as appropriate. Fastener spacing for the interior stud nail lines was $305 \mathrm{~mm}$ (12 in).

Simpson Strong-Tie hold-downs (Models HTT4 and HTT22) were used for the wall specimens with $15-\mathrm{cm}$ sheathing fastener spacing. The HTT4 and HTT22 hold-downs were attached to the chord members with screws and 10d nails respectively. Both connectors had the same design values. The Model HDU8 hold-down was used for the test specimens with closer fastener spacings. It was attached to the end studs with 75-mm (3-in) Simpson Strong-Tie SDS screws. 
Table 1. Shear wall test specimens' configuration

\begin{tabular}{|c|c|c|c|c|c|c|c|}
\hline \multirow{2}{*}{$\begin{array}{l}\text { Wall } \\
\text { name }\end{array}$} & \multirow{2}{*}{$\begin{array}{l}\text { Spacing } \\
\mathrm{cm} \text { (in) }\end{array}$} & \multirow[b]{2}{*}{ Test \# } & \multirow[b]{2}{*}{ Load } & \multicolumn{2}{|c|}{ Hold-down } & \multirow{2}{*}{$\begin{array}{c}\text { Intermediate } \\
\text { stud / } \\
\text { Number of } \\
\text { stitch screws }\end{array}$} & \multirow{2}{*}{$\begin{array}{l}\text { Edge } \\
\text { distance } \\
\text { mm (in) }\end{array}$} \\
\hline & & & & Model & Fastener & & \\
\hline ST1-2-S & $5(2)$ & 1 & Static & HTT4 & 1.5 -in s & single & $19(3 / 4)$ \\
\hline ST1-2-S & $5(2)$ & 2 & Static & HTT4 & 2.5 -in & single & $19(3 / 4)$ \\
\hline ST1-2-C & $5(2)$ & $1-2-3$ & Cyclic & HDU8 & 3-in SDS & double/6 & $19(3 / 4)$ \\
\hline ST1-4-S & 10( & 1 & Static & HTT22 & $10 \mathrm{~d}$ & single & $19(3 / 4)$ \\
\hline ST1-4-C & 10( & $1-2$ & Cyclic & HTT22 & $10 \mathrm{~d}$ & single & $19(3 / 4)$ \\
\hline ST1-4-C & $10(4)$ & $3-4$ & Cyclic & HDU8 & 3 -in & double/10 & $10(3 / 8)$ \\
\hline ST1-6-S & $15(6)$ & 1 & Static & HDU8 & 3-in SDS & double/10 & $10(3 / 8)$ \\
\hline ST1-6-C & $15(6)$ & $1-2-3$ & Cyclic & HDU8 & 3 -ins & double/10 & $10(3 / 8)$ \\
\hline N1-4-S & $10(4)$ & $1-2$ & Static & HDU8 & $3-\mathrm{i}$ & double/10 & $10(3 / 8)$ \\
\hline N1-4-C & $10(4)$ & $1-2-3$ & Cyclic & HDU8 & 3-in SDS & double/10 & $10(3 / 8)$ \\
\hline N1-6-S & $15(6)$ & $1-2$ & Static & HDU8 & 3-in SDS & double/10 & $10(3 / 8)$ \\
\hline N1-6-C & $15(6)$ & $1-2-3$ & Cyclic & HDU8 & 3-in SDS & double/10 & $10(3 / 8)$ \\
\hline
\end{tabular}

The screws used to connect the hold-downs to the end studs (chords) penetrated both stud elements, to ensure that the load was distributed more uniformly from the end studs to the hold-downs and separation of the end studs during the cyclic tests is avoided. The hold-downs were attached to the foundation with a $12.5-\mathrm{mm}(1 / 2-$ in $)$ diameter threaded rods, where the hole was enlarged to $16 \mathrm{~mm}$ (5/8 in.) Like the rods, the anchor bolts were $12.5 \mathrm{~mm}(1 / 2$ in) in diameter. The washers for the anchor bolts were $75 \times 75 \times 6 \mathrm{~mm}(3 \times 3 \times 1 / 4$ in) steel plates.

Furthermore, the bottom plate was attached to the steel test fixture plate with clamps on each end of the wall to restrict the horizontal slip displacement of the bottom plates, and thereby induced the maximum racking deformation of the walls. The sheathing panels were gapped $3 \mathrm{~mm}(1 / 8 \mathrm{in})$ as should be done in the field to accommodate potential changes in the moisture content of the panels. The walls were constructed following the ASTM E72 (ASTM 2015b) standard requirements.

\section{Setup}

The test setup is located in the Department of Wood and Forest Sciences at the Universite Laval, Canada and is shown in Figure 1. The test fixture is constructed of steel wide flange columns and diagonal braces connected with bolts. A horizontal HSS beam bolted to the columns provides support to another horizontal beam through ball-bearing tracks allowing the upper beam to roll freely along the tracks and transfer the load from the actuator to the test specimen. The actuator is connected to the upper beam and applies the load to the specimen through two C-channels welded to steel plates attached to the top plate of the wall using self-drilling screws. In contrast with the "standard connection", which usually consists of a big I-beam over the wall where the actuator applies the load, the C-channels used in these tests are less rigid than the standard connection, therefore, the deformation pattern of the wall more closely replicates reality than is possible in most other test fixtures. To measure the displacement of the specimens, five laser displacement measuring instruments are used and located as shown in Figure 1. 


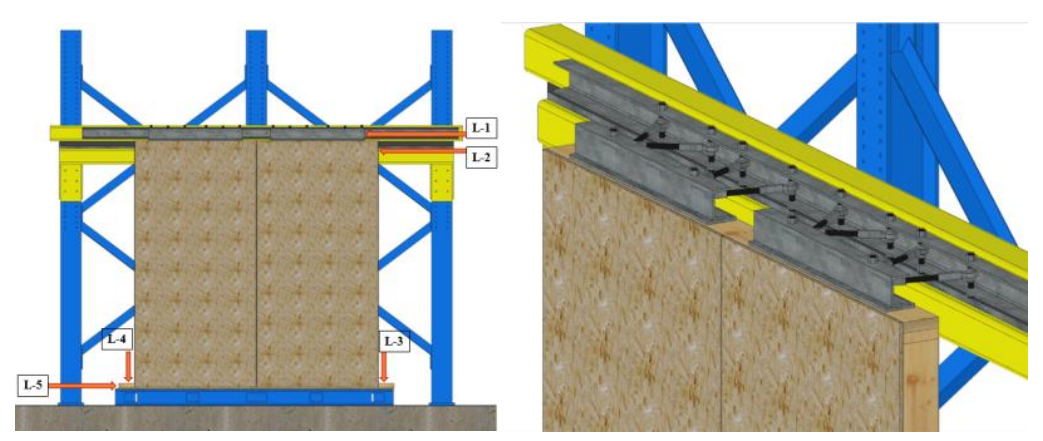

Figure 1. Test Setup.

\section{Test procedure}

The walls were tested using monotonic and cyclic loads following the ASTM E2126 (ASTM 2011) Method C (CUREE) protocol. According to Krawinkler et al. (2001), the protocol was developed with emphasis on the performance of the wall and the statistical simulation of demand contributing significantly to damage at the 10/50 hazard level, as well as adequate simulation of potentially damaging cycles at hazard levels associated with higher performance levels.

\section{RESULTS AND DISCUSSION}

The test results are summarized in Table 2. For each test, a load-displacement curve (hysteretic curve in case of cyclic tests) was plotted, along with the backbone curve and the equivalent energy elastic-plastic (EEEP) curve following the ASTM E2126 (ASTM 2011) standard procedure. The drift capacity, overstrength, and ductility ratio were estimated following the ASTM D7989 (ASTM 2015a) standard procedure. Monotonic load-displacement curves and cyclic test backbone curves (average of positive and negative envelopes) for walls with nails and staples are shown in Figures $2 \mathrm{a}$ and $2 \mathrm{~b}$, respectively. The responses of the nailed and stapled shear walls look similar for the 10- and 15-cm (4- and 6-in) fastener spacings. It can also be seen that while the load resistance for the stapled walls increases with closer fastener spacing, the displacement also decreases.

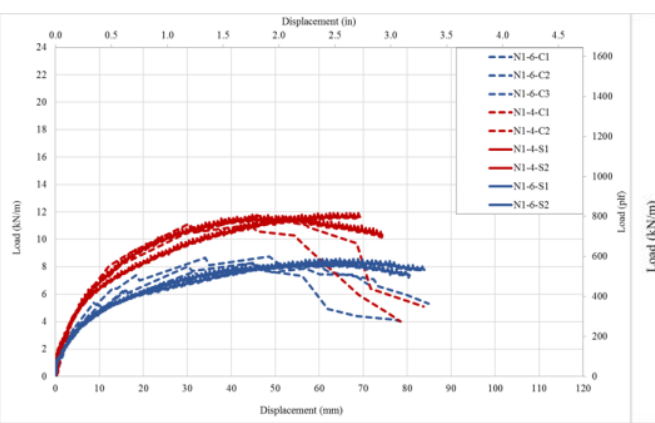

(a) Nailed Walls

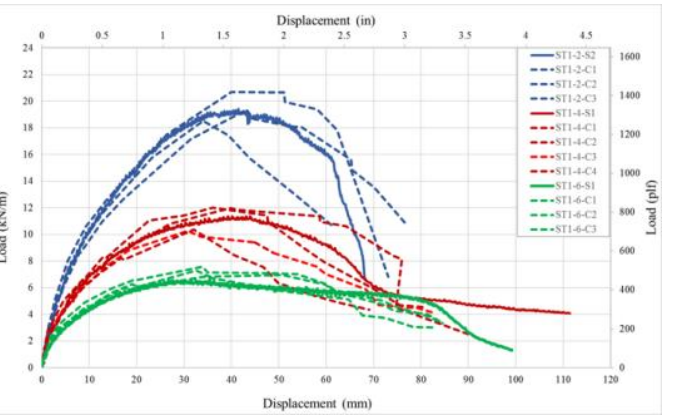

(b) Stapled Walls

Figure 2. Load-displacement and backbone curves. (excluding displacement due to rigid-body rotation).

The failure modes observed during the tests on walls with nails and staples are shown in Figures $3 a$ and $3 b$, respectively. Three principal modes of failure were observed for the sheathing fasteners: 1) fastener withdrawal from the framing, 2) fastener head pull-through the sheathing, and 3) fastener tear-out through the sheathing edge. Often, the observed overall failure of the wall was a combination of the three modes described, which resulted in a loss in the shear resistance of the 


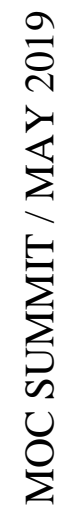

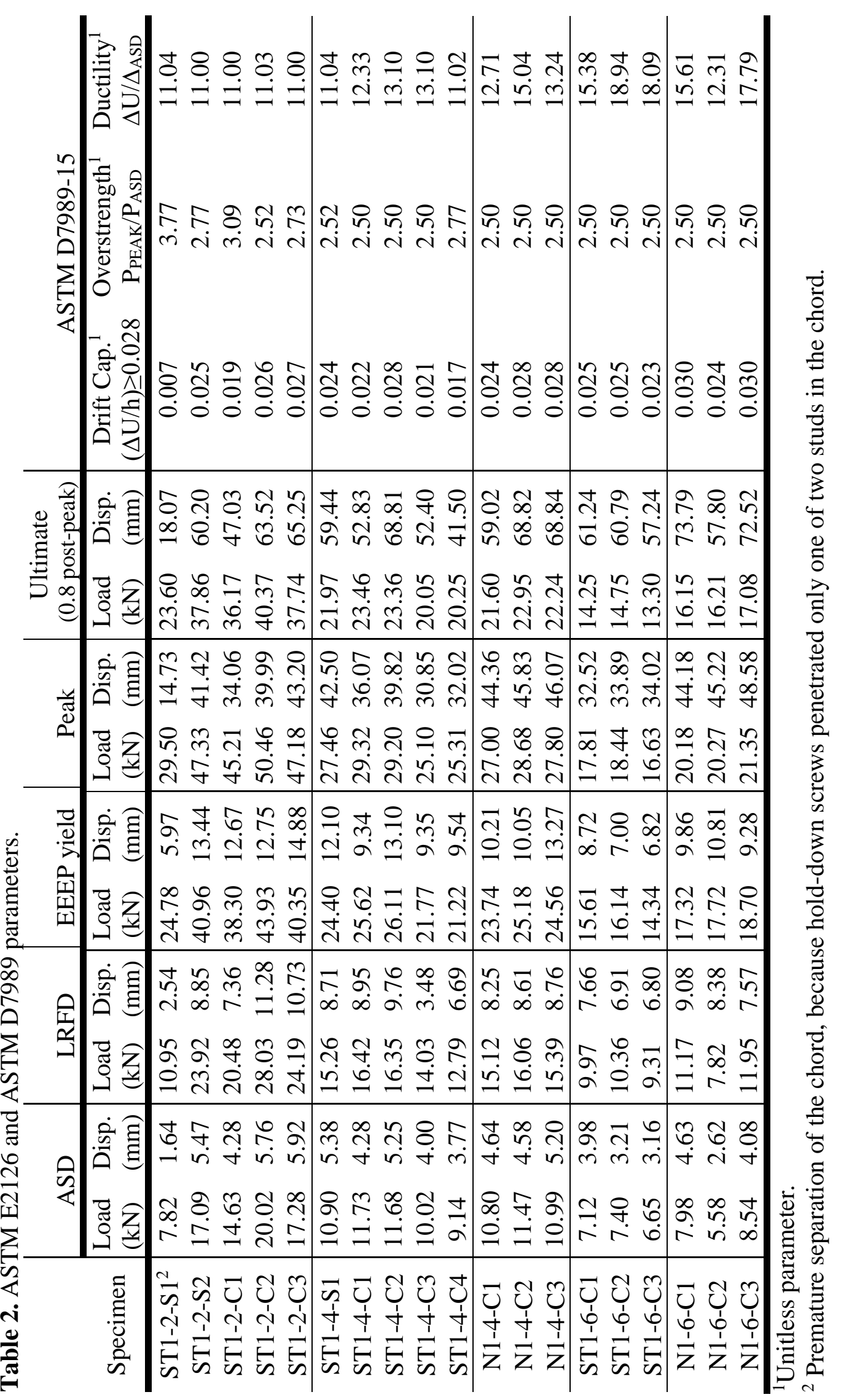


specimen. Splitting of framing (horizontal and vertical elements) was significantly more common when nails were used to attach the sheathing than when staples were used during the cyclic tests, especially when the edge distance of the fastener in the framing was small. Also, the tear-out failure mode occurred when the panel edge distance was small.

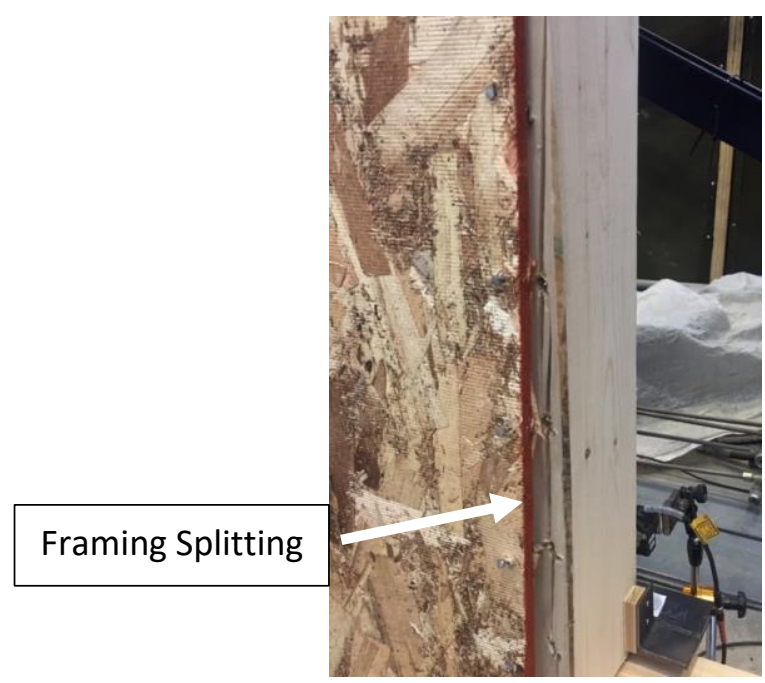

(a) nailed

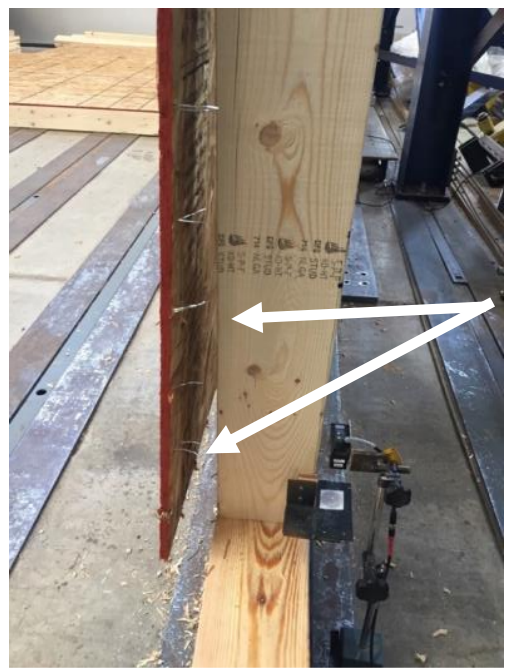

(b) stapled

Fastener withdrawal

Figure 3. Principle failure modes in walls.

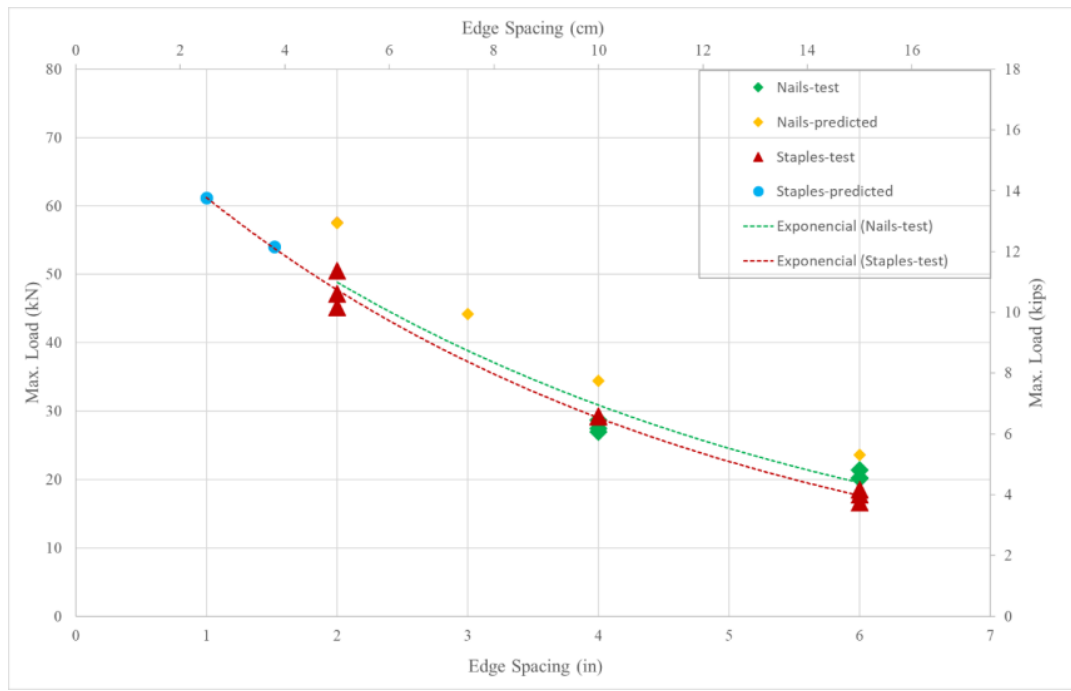

Figure 4. Maximum load (kN) v/s Edge Spacing (in).

The relationship between load capacity and the perimeter fastener spacing is shown in Figure 4. It was possible to estimate the maximum average load for stapled walls with $2.5-\mathrm{cm}$ (1-in) and 3.8$\mathrm{cm}$ (1.5-in) edge spacing by extending an exponential curve that was fit to the experimental tests. The average load capacities for nailed shear walls were estimated as three times the allowable design values determined using the nominal values presented in the SDPWS (2008) and adjustments for sheathing type, framing species, and 3-in nominal framing as required for 5-cm (2in) nail spacing. Note that in all cases, the estimates are all slightly higher than the experimental results. These values may be useful as a design information and in design tools because staples are less likely to split the framing at close spacing, and therefore could be used with $38 \mathrm{~mm}$ (2-in nominal) framing. If an exponential trend line were assumed for the nail spacing relationship, both 
types of fasteners provide equivalent resistances for closely spaced fasteners, but the nailed walls would require 3-in nominal framing be used. This shows that walls with very closely spaced staples should be tested to ensure that the framing would not split excessively, if reasonably high capacity walls were desired with 38-mm (2-in nominal) framing to reduce the cost associated with the higher capacity walls.

A comparison of the deflection estimations obtained using the 3- and 4-term equations in the SDPWS (AWC 2008) versus the wall test results for specimens with perimeter fastener spacing of $10 \mathrm{~cm}$ (4 in) are shown in Figure 5. It is important to highlight the difference between the experimental and theoretical estimates at the ASD and LRFD load levels. The deflection of the shear walls was almost four times higher than the equations estimated at both the ASD and LRFD design levels. In other words, the equations are non-conservative by a factor of 4.0. This issue is being investigated further and will be included in a journal article that has been submitted for review and publishing.

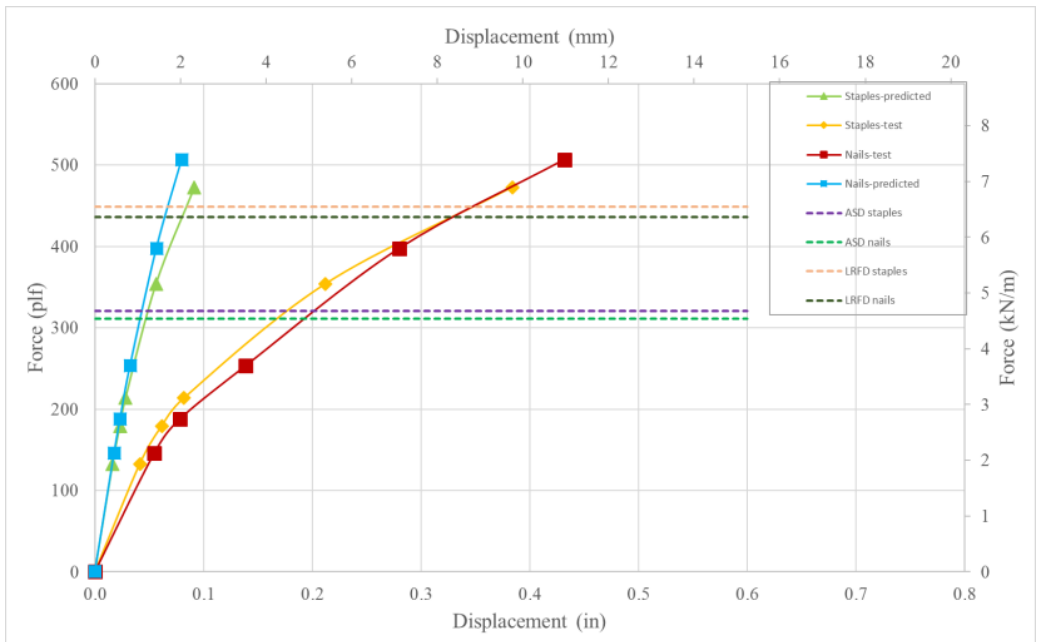

Figure 5. Comparison of deflection estimation using 3- and 4-term equations versus experimental data for $10 \mathrm{~cm}$ (4 in) perimeter fastener spacing (excluding displacement due to rigid-body rotation).

\section{CONCLUSION}

This paper reported the results of an experimental investigation of the performance of nailed and stapled shear walls under monotonic and cyclic loading following ASTM E564, E2126, and D7989 testing and analysis procedures. The test results show a similar performance for nailed and stapled shear walls with 15-cm (6-in) and 10-cm (4-in) perimeter fastener spacing, and it is speculated that stapled shear walls may have significantly better performance than nailed shear walls at close sheathing fastener spacing $(5.0 \mathrm{~cm}$ ( 2 in) or less) due to their lower tendency to cause splitting in the framing at close fastener spacing. It is important to consider the detailing of the shear walls, especially if the sheathing fasteners are closely spaced and/or the end/edge distance of the fasteners in sheathing panel are small. The results show that the staples can achieve equal strength and stiffness to nailed shear walls at $15 \mathrm{~cm}(6 \mathrm{in})$ and $10 \mathrm{~cm}$ (4 in) fastener spacing. Also, the tests have shown that stapled shear walls have significantly less framing splitting issues at close fastener spacing (or smaller edge distance at the same spacing) than nailed shear walls. It is deduced that it is possible to reach higher strength values in stapled walls if the edge distance is reduced to $5 \mathrm{~cm}$ (2-in), 3.8-cm (1.5-in) or 2.5-cm (1-in), which would not be feasible with nailed walls. 
The 3- and 4-term equations in the SPDWS (AWC 2008) used to estimate deflection for shear walls are also compared to the wall test data for $10-\mathrm{cm}$ (4-in) fastener spacing to illustrate a potential problem with accuracy. This issue will be investigated more thoroughly in a companion manuscript that has been submitted for review and publication. This research has shown that at the ASD and LRFD load levels the 3-term and 4-term equation, the equations underestimate the deflections by as much as a factor of four.

\section{ACKNOWLEDGEMENTS}

This research was sponsored in part by the Canadian Natural Sciences and Engineering Research Council (NSERC) Grant no. RGPIN-2017-05890. It was also made possible due to an internship of Roberto Aranda at the Renewable Materials Research Centre (CRMR) of Université Laval in Quebec City, Quebec, Canada, funded by the Government of Canada Emerging Leaders in the Americas Program (ELAP) International Scholarship \#168411.

\section{REFERENCES}

American Wood Council (AWC). 2008. ANSI/AWC. "Special Design Provisions for Wind and Seismic with commentary." AWC, Washington, DC.

ASTM. Standard E564, 2006 (2018). "Standard practice for static load test of shear resistance of framed walls for buildings." ASTM International, West Conshohocken, PA, 2006, DOI: 10.1520/E0564-0.6R18, www.astm.org.

ASTM. Standard E2126, 2011. "Standard test method for cyclic (reversed load test for shear resistance of vertical elements of the lateral force resisting systems for buildings." ASTM International, West Conshohocken, PA, 2011, DOI: 10.1520/E2126-11, www.astm.org.

ASTM Standard D7989, 2015a. "Standard practice for demonstrating equivalent in plane lateral seismic performance to wood-frame shear walls sheathed with wood structural panels." ASTM International, West Conshohocken, PA, 2015, DOI: 10.1520/D7989-15. www.astm.org

ASTM. Standard E72, 2015b. "Standard test methods of conducting strength tests of panels for building construction." ASTM International, West Conshohocken, PA, 2015, DOI: 10.1520/E0072-15. www.astm.org.

Dolan, J.D. (1989). Dynamic response of timber shear walls. Dissertation completed as partial fulfillment of the requirements for the Ph.D. degree at the University of British Columbia.

Gatto, K., and Uang, C-M. (2003). "Cyclic response of wood frame shearwalls: Loading protocol and rate of loading effects." No. W-13, CUREE-Caltech Woodframe Project, Richmond, CA.

Kassal, B. and R.J. Leichti (1992). "Nonlinear finite-element model for light-frame stud walls." ASCE Journal of Structural Engineering. Reston, VA.

Krawinkler, H., Parisi, F., Inarra, L. Ayoub, A. and Medina, R. (2001). "Development of a testing protocol for wood frame structures." CUREE-Caltech Woodframe Project, CUREE, Richmond, CA.

Leichti, R., Anderson, E., Sutt, E., and Rosowsky, D. (2006). "Sheathing nail bending yield strength-role in shear wall performances" Proc., $9^{\text {th }}$ World Conf. on Timber Engineering, Oregon State University Conference Services, Corvallis, OR. 203-210.

Salenikovich, A. J. (2000). The racking performance of light-frame shear walls. Dissertation completed as partial fulfillment of the requirements for the Ph.D. degree at Virginia Polytechnic Institute and State University. Blacksburg, VA.

Toothman, A.J. (2003). Monotonic and cyclic performance of light-frame shear walls with various sheathing materials. Thesis completed as partial fulfillment of the requirements for the Master of Science degree at Virginia Polytechnic Institute and State University. Blacksburg, VA. 